\title{
Effects of Exogenous Abscisic Acid on Resistance of Capsella bursa-pastoris Under Salt Stress
}

\author{
Yumei Tan ${ }^{1, a}$, Jianhua $\mathrm{Li}^{2, \mathrm{~b}}$, Huan Yao ${ }^{1, \mathrm{c}}$, Zicheng Lü ${ }^{3, \mathrm{~d}}$, Maolin $\mathrm{Chen}^{4, \mathrm{e}}$, \\ Mei Qing ${ }^{1, f}$ and Lijin Lin ${ }^{5, g^{*}}$
}

${ }^{1}$ College of Horticulture, Sichuan Agricultural University, Chengdu, Sichuan, China

2Sichuan Ya'an Municipal Product Quality Supervision \& Inspection Institute, Ya'an, Sichuan, China

${ }^{3}$ College of Agronomy, Sichuan Agricultural University, Chengdu, Sichuan, China

${ }^{4}$ College of Economics, Sichuan Agricultural University, Chengdu, Sichuan, China

${ }^{5}$ Institute of Pomology and Olericulture, Sichuan Agricultural University, Chengdu, Sichuan, China

a2229809882@qq.com, b710753781@qq.com, c272365026@qq.com, dizcheng666@qq.com, e3208585092@qq.com, f1115435013@qq.com, 9lj800924@163.com

${ }^{*}$ Corresponding author. Yumei Tan and Jianhua Li contributed equally to this work.

Keywords: Capsella bursa-pastoris; Abscisic acid; Antioxidant enzyme activity; Growth

Abstract: A pot experiment was carried out to study the effects of exogenous abscisic acid (ABA) on the resistance of Capsella bursa-pastoris under salt stress. Spraying ABA increased the root, stem, leaf and shoot biomasses of $C$. bursa-pastoris under salt stress. ABA applications also enhanced the plant height of $C$. bursa-pastoris. With the increase in the ABA concentrations, the biomass and plant height of $C$. bursa-pastoris increased. ABA treatments enhanced the antioxidant enzyme (SOD, POD and CAT) activities of $C$. bursa-pastoris. With increasing ABA concentrations, the SOD, CAT and POD activities of $C$. bursa-pastoris were enhanced under salt stress and the soluble protein content of C. bursa-pastoris also showed an increasing trend. Therefore, ABA could enhance the resistance of $C$. bursa-pastoris to salt stress, and promote its growth.

\section{Introduction}

Capsella bursa-pastoris is a common wild vegetable with a strong nutritional value [1-2]. However, because of irrational fertilization, vegetable fields have become overly salinized, which has serious effects on C. bursa-pastoris production [2]. Therefore, to enhance the resistance of C. bursa-pastoris to salt stress, different concentrations of abscisic acid (ABA) were used to treat $C$. bursa-pastoris seedlings. The aim of this study was to determine the optimal ABA concentration for enhancing the resistance of $C$. bursa-pastoris to salt stress, and to provide a reference for improving salt resistance in vegetable species.

\section{Materials and Methods}

Materials. Seedlings of $C$. bursa-pastoris with five euphyllas were collected from the Chengdu Campus of Sichuan Agricultural University $\left(30^{\circ} 42^{\prime} \mathrm{N}, 103^{\circ} 51^{\prime} \mathrm{E}\right)$ in October 2015 . The culture medium in the experiment was a 1:1 mixture of perlite and vermiculite.

Experimental Design. The culture medium was placed into polyethylene pots $(10 \mathrm{~cm}$ high, $10 \mathrm{~cm}$ in diameter), and three uniform seedlings of C. bursa-pastoris were transplanted into each pot. The plant seedlings were irrigated with $20 \mathrm{~mL}$ Hoagland nutrient solution (containing $50 \mathrm{mmol} / \mathrm{L} \mathrm{NaCl}$ ) [2] per pot every two days until the plants were harvested. When C. bursa-pastoris seedlings had grown for 15 days, five concentrations $(0,1,5,10$ and $20 \mu \mathrm{mol} / \mathrm{L})$ of $\mathrm{ABA}$ [3], with three replicates, were sprayed independently on the leaves of plants. The second and third ABA sprayings occurred at 18 days and 21 days after transplanting, respectively. At each spraying, $25 \mathrm{~mL}$ of ABA solution was used per pot, which just soaked the plants. 30 days after the last ABA spraying, the plant height of each $C$. bursa-pastoris was measured. Then, the whole plants were then harvested, and the roots, 
stems and leaves were washed with tap water and dried with absorbent paper for weighing the fresh biomasses.

Statistical Analyses. Statistical analyses were performed using SPSS 13.0 statistical software (IBM, Chicago, IL, USA). Data were analyzed by a one-way analysis of variance with least significant difference at a 5\% confidence level.

\section{Results and Discussion}

Biomass of $\boldsymbol{C}$. bursa-pastoris. Spraying ABA increased the root, stem, leaf and shoot biomasses of $C$. bursa-pastoris (Table 1). When the doses of ABA were 1 and $5 \mu \mathrm{mol} / \mathrm{L}$, there were no significant differences in the root biomasses compared with that of the control. ABA at 10 and $20 \mu \mathrm{mol} / \mathrm{L}$ increased the root biomass of C. bursa-pastoris by $5.48 \%(p<0.05)$ and $6.30 \%(p<0.05)$, respectively, compared with the control. When the ABA concentrations were $1,5,10$ and $20 \mu \mathrm{mol} / \mathrm{L}$, the shoot biomass of $C$. bursa-pastoris increased by $6.13 \%(p<0.05), 12.51 \%(p<0.05), 20.97 \%(p$ $<0.05)$ and $8.40 \%(p<0.05)$, respectively, compared with the control. ABA applications also enhanced the plant height of $C$. bursa-pastoris, which increased by $4.54 \%(p>0.05), 6.47 \%(p>$ $0.05), 8.40 \%(p<0.05)$ and $10.42 \%(p<0.05)$. Thus, ABA can promote the growth of $C$. bursa-pastoris under salt stress.

When plants are under stress conditions, their bodies rapidly synthesize a large amount of ABA to enhance their resistance to the environmental stress [4]. The application of exogenous ABA can promote the rapid synthesis of ABA, and enhance the plant's salt resistance [5]. Under salt stress, the exogenous ABA promotes the growth of maize seedlings and increases their biomass [6]. In this experiment, the exogenous ABA increased the root, stem, leaf and shoot biomasses of $C$. bursa-pastoris. ABA applications also enhanced the plant height of $C$. bursa-pastoris. With the increase in the ABA concentrations, the biomass and plant height of $C$. bursa-pastoris increased. These results were consistent with those of other studies [6-7]. Therefore, exogenous ABA could promote the growth of $C$. bursa-pastoris by increasing the biomass and enhancing the plant height under salt stress, with the optimal ABA dose of ABA being $20 \mu \mathrm{mol} / \mathrm{L}$ in this experiment.

Table 1 Biomass of Capsella bursa-pastoris

\begin{tabular}{|c|c|c|c|c|c|}
\hline $\begin{array}{c}\text { ABA } \\
\text { concentrations } \\
(\mu \mathrm{mol} / \mathrm{L})\end{array}$ & $\begin{array}{c}\text { Root biomass } \\
(\mathrm{g} / \text { plant })\end{array}$ & $\begin{array}{c}\text { Stem biomass } \\
(\mathrm{g} / \text { plant })\end{array}$ & $\begin{array}{c}\text { Leaf biomass } \\
(\mathrm{g} / \mathrm{plant})\end{array}$ & $\begin{array}{c}\text { Shoot biomass } \\
(\mathrm{g} / \mathrm{plant})\end{array}$ & $\begin{array}{c}\text { Plant height } \\
(\mathrm{cm})\end{array}$ \\
\hline 0 & $0.492 \pm 0.012 \mathrm{~b}$ & $1.155 \pm 0.012 \mathrm{~b}$ & $1.634 \pm 0.008 \mathrm{e}$ & $2.789 \pm 0.020 \mathrm{e}$ & $20.72 \pm 1.15 \mathrm{~b}$ \\
\hline 1 & $0.507 \pm 0.010 \mathrm{ab}$ & $1.167 \pm 0.015 \mathrm{~b}$ & $1.793 \pm 0.038 \mathrm{~d}$ & $2.960 \pm 0.053 \mathrm{~d}$ & $21.66 \pm 0.87 \mathrm{ab}$ \\
\hline 5 & $0.512 \pm 0.008 \mathrm{ab}$ & $1.203 \pm 0.014 \mathrm{a}$ & $1.935 \pm 0.021 \mathrm{c}$ & $3.138 \pm 0.035 \mathrm{c}$ & $22.06 \pm 1.33 \mathrm{ab}$ \\
\hline 10 & $0.519 \pm 0.006 \mathrm{a}$ & $1.213 \pm 0.010 \mathrm{a}$ & $2.161 \pm 0.027 \mathrm{~b}$ & $3.374 \pm 0.037 \mathrm{~b}$ & $22.46 \pm 1.21 \mathrm{a}$ \\
\hline 20 & $0.523 \pm 0.013 \mathrm{a}$ & $1.224 \pm 0.016 \mathrm{a}$ & $2.321 \pm 0.041 \mathrm{a}$ & $3.545 \pm 0.057 \mathrm{a}$ & $22.88 \pm 0.95 \mathrm{a}$ \\
\hline
\end{tabular}

Values are means $( \pm \mathrm{SE})$ of three replicate pots. Different lowercase letters within a column indicate significant differences based on a one-way analysis of variance in SPSS 13.0 followed by the least significant difference test $(p<0.05)$.

Antioxidant enzyme activities and the soluble protein content of $\boldsymbol{C}$. bursa-pastoris. ABA treatments enhanced the antioxidant enzyme (SOD, POD and CAT) activities of $C$. bursa-pastoris (Table 2). The activities of SOD, POD and CAT increased with increasing ABA concentrations. When the ABA concentrations were 1, 5, 10 and $20 \mu \mathrm{mol} / \mathrm{L}$, the SOD activities were enhanced by $18.42 \%(p<0.05), 29.50 \%(p<0.05), 44.25 \%(p<0.05)$ and $51.54 \%(p<0.05)$, respectively, the POD activities were enhanced by $0.60 \%(p>0.05), 33.01 \%(p<0.05), 39.36 \%(p<0.05)$ and $51.22 \%$ $(p<0.05)$, respectively, and the CAT activities were enhanced by $20.58 \%(p<0.05), 75.83 \%(p<$ $0.05), 136.15 \%(p<0.05)$ and $188.65 \%(p<0.05)$, respectively, compared with those of the control. The ABA applications also increased C. bursa-pastoris' soluble protein content, which increased with increasing ABA concentrations (Table 2). When the ABA concentrations were 1, 5, 10 and 20 
$\mu \mathrm{mol} / \mathrm{L}$, the soluble protein contents increased by $4.58 \%(p>0.05), 18.81 \%(p<0.05), 21.62 \%(p<$ $0.05)$ and $33.28 \%(p<0.05)$, respectively, compared with the control. Thus, ABA could enhance the resistance of $C$. bursa-pastoris to salt stress.

In the normal physiological state, the active oxygen in the plant body is relatively stable, and the antioxidant enzyme system is inhibited when the plant is injured [8]. Under salt stress conditions, the reactive oxygen species accumulated in the plant will accumulate and eventually destroy the membrane structure, causing metabolic disorders [9]. SOD, CAT and POD are three important antioxidant enzymes in the plant body that can effectively scavenge free radicals and maintain the free radical metabolic balance to ensure normal growth and can regulate the metabolisms of membrane systems to enhance the plant resistance [8-10]. Under adverse conditions, plants produce a series of physiological and biochemical changes to induce a number of specific gene expressions, which produce proteins, and thus play a protective role [11]. ABA, as a stress signal substance, is directly involved in the expression of many stress response genes [12]. Under salt stress, exogenous ABA significantly enhances the SOD, CAT and POD activities of cucumber seedlings [13] and increases the soluble protein content of maize seedlings [6]. Thus, exogenous ABA can enhance the resistance of plants to salt stress. In this experiment, with increasing ABA concentrations, the SOD, CAT and POD activities of C. bursa-pastoris were enhanced under salt stress and the soluble protein content of $C$. bursa-pastoris also showed an increasing trend. These results indicate that ABA could enhance the resistance of $C$. bursa-pastoris to salt stress, which ensures its normal growth.

Table 2 Antioxidant enzyme activities and the soluble protein content of Capsella bursa-pastoris

\begin{tabular}{|c|c|c|c|c|}
\hline $\begin{array}{c}\text { ABA concentrations } \\
(\mu \mathrm{mol} / \mathrm{L})\end{array}$ & $\begin{array}{c}\text { SOD activity } \\
(\mathrm{U} / \mathrm{g})\end{array}$ & $\begin{array}{c}\text { POD activity } \\
(\mathrm{U} / \mathrm{g})\end{array}$ & $\begin{array}{c}\text { CAT activity } \\
(\mathrm{U} / \mathrm{g})\end{array}$ & $\begin{array}{c}\text { Soluble protein content } \\
(\mathrm{mg} / \mathrm{g})\end{array}$ \\
\hline 0 & $157.18 \pm 3.99 \mathrm{c}$ & $3293.7 \pm 66.89 \mathrm{~d}$ & $18.95 \pm 0.14 \mathrm{e}$ & $12.44 \pm 0.04 \mathrm{c}$ \\
\hline 1 & $186.14 \pm 6.77 \mathrm{~b}$ & $3313.4 \pm 56.46 \mathrm{~d}$ & $22.85 \pm 1.27 \mathrm{~d}$ & $13.01 \pm 1.00 \mathrm{c}$ \\
\hline 5 & $203.55 \pm 5.28 \mathrm{~b}$ & $4381.0 \pm 26.94 \mathrm{c}$ & $33.32 \pm 1.71 \mathrm{c}$ & $14.78 \pm 0.10 \mathrm{~b}$ \\
\hline 10 & $226.73 \pm 7.91 \mathrm{a}$ & $4590.1 \pm 21.00 \mathrm{~b}$ & $44.75 \pm 1.26 \mathrm{~b}$ & $15.13 \pm 0.37 \mathrm{ab}$ \\
\hline 20 & $238.19 \pm 10.56 \mathrm{a}$ & $4980.8 \pm 85.98 \mathrm{a}$ & $54.70 \pm 0.99 \mathrm{a}$ & $16.58 \pm 0.98 \mathrm{a}$ \\
\hline
\end{tabular}

Values are means $( \pm \mathrm{SE})$ of three replicate pots. Different lowercase letters within a column indicate significant differences based on a one-way analysis of variance in SPSS 13.0 followed by the least significant difference test $(p<0.05)$.

\section{Conclusions}

Under salt stress, spraying ABA increased the root, stem, leaf and shoot biomasses of $C$. bursa-pastoris. ABA applications also enhanced the plant height of $C$. bursa-pastoris. With the increase in the ABA concentrations, the biomass and plant height of $C$. bursa-pastoris increased. ABA treatments enhanced the antioxidant enzyme (SOD, POD and CAT) activities of $C$. bursa-pastoris. With increasing ABA concentrations, the SOD, CAT and POD activities of $C$. bursa-pastoris were enhanced under salt stress and the soluble protein content of $C$. bursa-pastoris also showed an increasing trend. Therefore, ABA could enhance the resistance of C. bursa-pastoris to salt stress, and promote its growth.

\section{Acknowledgements}

This work was financially supported by the 2016 Innovation Training Program of University Student (201610626032) and the Application Infrastructure Project of Science and Technology Department of Sichuan Province (2016JY0258). 


\section{References}

[1] X.M. Huang and J. Cai: Food and Drug Vol. 7 (2005), p. 66.

[2] X.L. Yu, B.J. Zhang and X.P. Wang: Journal of Anhui Agricultural Sciences Vol. 40 (2012), p. 8864.

[3] J. Wang, L. Lin, L. Luo, M. Liao, L. Lv, Z. Wang, D. Liang, H. Xia, X. Wang, Y. Lai and Y. Tang: Environmental Monitoring and Assessment Vol. 188 (2016), p. 182.

[4] H. Jia and C. Lu: Plant Science Vol. 165 (2003), p. 1403.

[5] P.C. Larosa, A.K. Handa and P.M. Hasegaawa: Plant Physiology Vol. 79 (1985), p. 138.

[6] K.F. Zhao, H. Fan and P.J.C. Harris: Acta Botanica Sinica Vol. 37 (1995), p. 295.

[7] A. Aienl, S. Khetarpal and M. Pal: American-Eurasian Journal of Agricultural \& Environmental Sciences Vol. 11 (2011), p. 633.

[8] E.F. Elster: Plant Biology Vol. 33 (1982), p. 73.

[9] A.J. Delauney and D.P.S. Verma: The Plant Journal Vol. 4 (1993), p. 215.

[10] H. Zhang: Journal of Anhui Agricultural Sciences Vol. 41 (2013), p. 490.

[11] N.K. Singh, A.K. Handa, P.M. Haseguwa and R. Bressan: Plant Physiology Vol. 79 (1985), p. 126.

[12] P.M. Chandler: Plant Molecular Biology Vol. 45 (1994), p. 113.

[13] X.R. Zhong, J.H.Yu, J.M. Xie, G.B. Zhang and Y.Z. Xu: Journal of Gansu Agricultural University Vol. 40 (2005), p. 467. 